\title{
Ischaemic optic neuropathy complicating cardiopulmonary bypass
}

\author{
D F P LARKIN,' A E WOOD,? M NELIGAN,? AND P EUSTACE'
}

From the Departments of ${ }^{1}$ Ophthalmology and ${ }^{2}$ Cardiac Surgery, Mater Misericordiae Hospital, Dublin 7

SUMMARY Bilateral anterior ischaemic optic neuropathy occurred in two patients undergoing cardiopulmonary bypass grafting. The causes may have been vasoconstriction of the posterior ciliary arteries by increased circulating angiotensin and diminished ciliary blood flow in the setting of systemic hypotension and elevated intraocular pressure.

A small number of visual complications of cardiopulmonary bypass have been described. Visual field disturbance, usually due to transient optic pathway ischaemia, and asymptomatic retinal emboli are the commonest.'

Anterior ischaemic optic neuropathy (AION) describes infarction of the optic nerve head, characterised by sudden painless loss of vision initially associated with optic disc oedema, resolving to optic atrophy. ${ }^{2}$ Hayreh has shown that the laminar and prelaminar regions of the optic nerve head and the peripapillary choroid are supplied by the posterior ciliary arteries. ${ }^{3}$ These arteries are susceptible to obliteration with fall in perfusion pressure, and the optic nerve head is thus vulnerable to infarction. AION is a relatively common cause of Correspondence to Prof. P Eustace. Eyc Department, Mater Misericordiac Hospital, Dublin 7, Ireland.

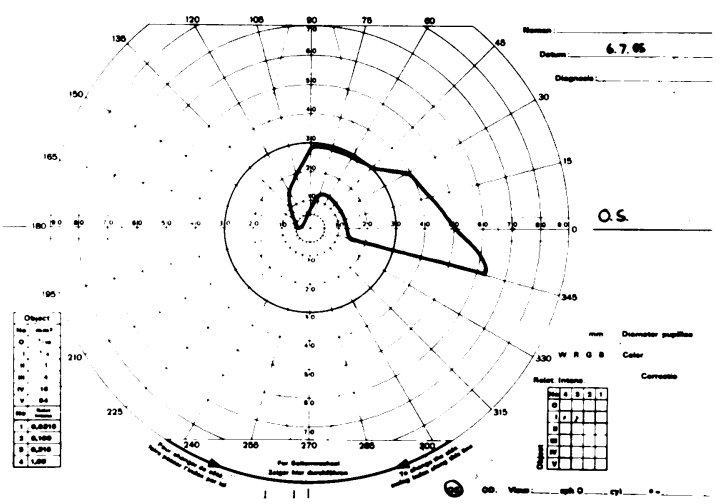

acute visual loss in the elderly. ${ }^{4}$ It has previously been described in cardiopulmonary bypass patients by Sweeney et al., but it is not listed in reviews of complications of bypass surgery. This paper reports two cases of bilateral AION resulting in severe visual impairment marring otherwise successful coronary artery surgery, and discusses pathogenesis.

\section{Case reports}

\section{CASE 1}

A 46-year-old man underwent coronary artery bypass graft surgery in which a membrane oxygenator and non-pulsatile perfusion were used for 74 minutes, with hypothermia $\left(28^{\circ} \mathrm{C}\right)$. Surgery and anaesthesia were apparently uncomplicated. When the patient regained mental alertness on the second postoperative day he complained of visual disturb-

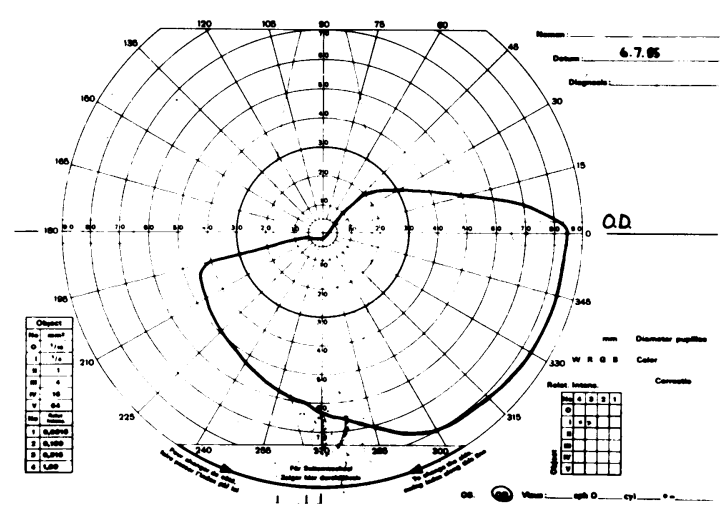

Fig. 1 Case 1. Left visual field loss inferiorly and superotemporally, leaving a small island of vision. Right superior altitudinal field defect. 

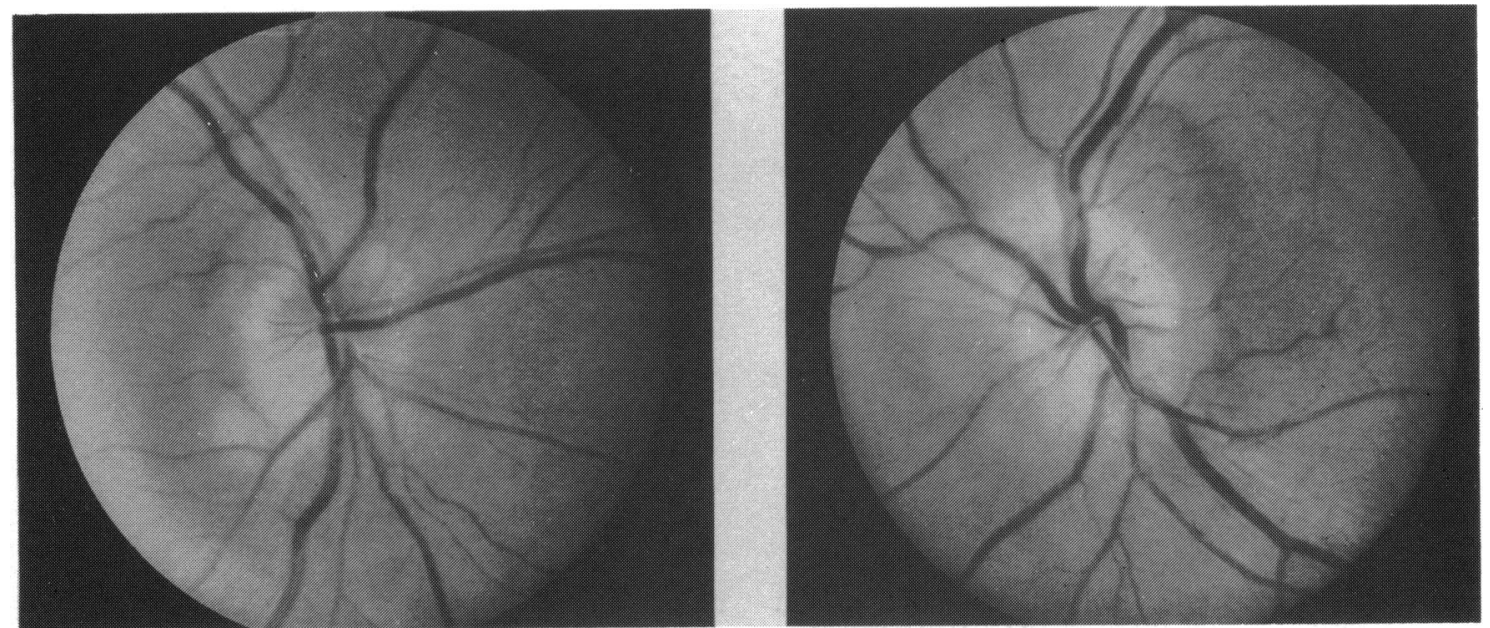

Fig. 2 Case 1. Optic disc swelling two days after surgery. A small left disc haemorrhage is seen at $2 o^{\prime}$ clock.

ance. On examination visual acuity was reduced in both eyes to counting fingers. Upper and lower altitudinal field defects (Fig. 1) and a left relative afferent pupil defect were noted. The optic discs showed diffuse pallid oedema with a left disc haemorrhage (Fig. 2). Examination was otherwise normal.

Fluorescein angiography showed bilateral optic disc leakage of dye, but no other abnormality of choroidal or retinal circulation. CT brain scan, packed cell volume, serum viscosity, and erythrocyte sedimentation rate were all normal. A diagnosis of AION was made. A course of corticosteroid was prescribed on an empirical basis, but visual acuity and field loss remained at the level noted at first assessment. Within 10 weeks optic atrophy was evident, particularly inferiorly on the right and superiorly on the left (Fig. 3).

\section{CASE 2}

A 63-year-old man underwent coronary artery bypass graft surgery in which a membrane oxygenator and non-pulsatile perfusion were used for 90 minutes, with hypothermia $\left(28^{\circ} \mathrm{C}\right)$. No complication was apparent until seven days following surgery, when he was examined on account of visual disturbance. Visual acuity was reduced to $3 / 60$ in both eyes; a superior visual field defect was noted in his right and a central scotoma in his left eye (Fig. 4). There was a left relative afferent pupil defect. Optic discs showed
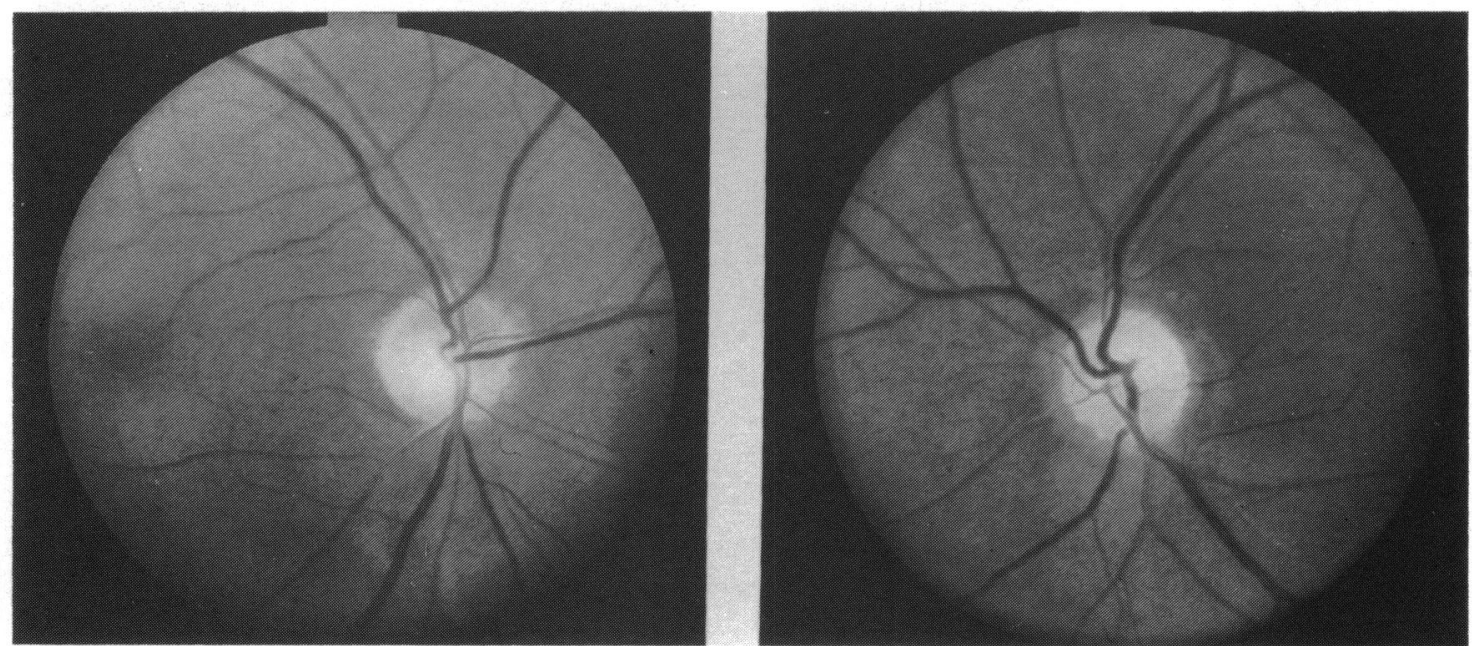

Fig. 3 Case 1. Optic atrophy 10 weeks after surgery. Pallor is greatest inferiorly in the right and superiorly in the left disc. 


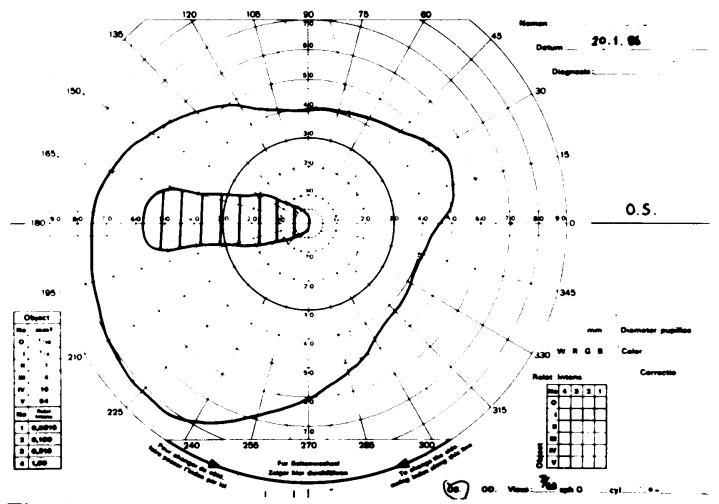

Fig. 4 Case 2. Visual fields at presentation.

florid bilateral pallid oedema with haemorrhages at the left disc margin (Fig. 5). He had no other neurological deficit.

Fluorescein angiography showed sectors of disc hypoperfusion and disc leakage of dye (Fig. 6). Investigations were otherwise normal. A diagnosis of AION was made, and no improvement in vision occurred.

\section{Discussion}

AION usually affects patients over the age of 50 years. It is an important cause of visual loss in this age group; any recovery of vision is unusual and no treatment has been shown to aid recovery. Hypertension, arterial disease, diabetes mellitus, and giant cell arteritis are commonly associated disorders. ${ }^{2}$ Bilateral simultaneous AION is rare, having been

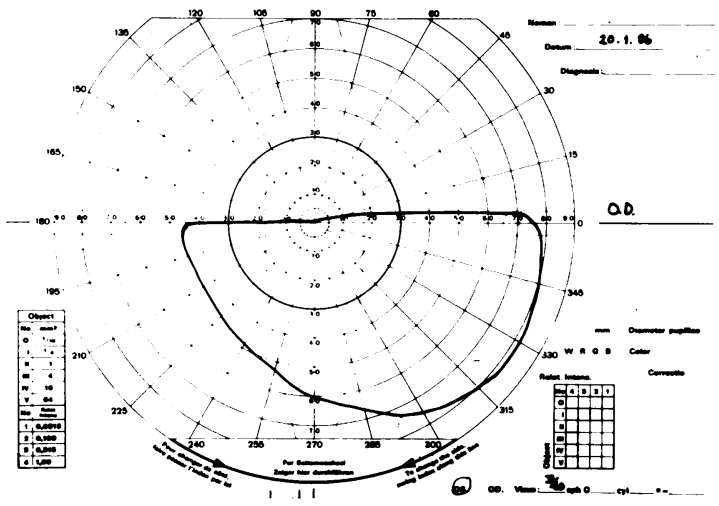

reported in cases of acute blood loss, ${ }^{6}$ diabetes, ${ }^{7}$ giant cell arteritis, ${ }^{8}$ and following cardiopulmonary bypass. ${ }^{5}$

The lamina cribrosa and the prelaminar region are the components of the optic nerve involved in AION. The posterior ciliary artery is the only supply to these regions, rendering them vulnerable to infarction. It is known that the posterior ciliary arteries need not be occluded, and emboli are considered rarely to cause AION. The arterial supply to the disc head passes through the surrounding choroid, which is under the influence of the intraocular pressure. As soon as artery perfusion pressure falls below the intraocular pressure, the disc circulation is compromised. ${ }^{2}$

Sweeney et al. ${ }^{5}$ reported seven cases of AION, of which three had bilateral lesions. Hypotensive episodes due to haemorrhage at surgery occurred in four cases. In addition, these authors considered

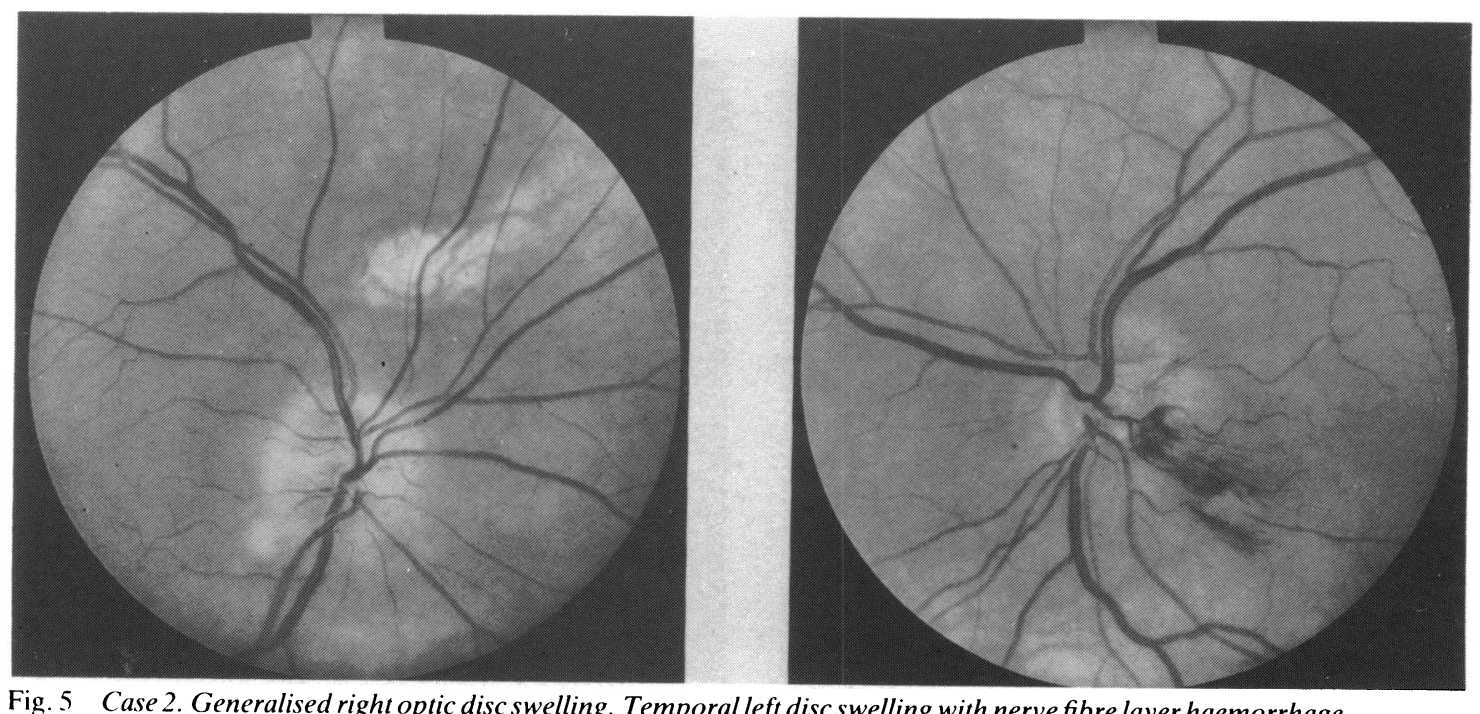

Fig. 5 Case 2. Generalised right optic disc swelling. Temporal left disc swelling with nerve fibre layer haemorrhage. 


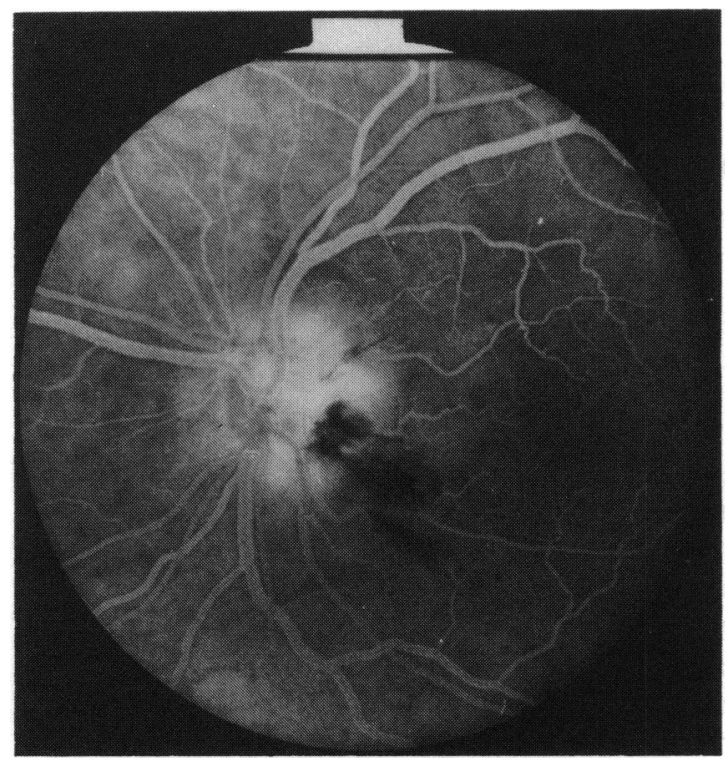

Fig. 6 Case 2. Late phase fluorescein angiogram of the left disc shows temporal leakage of dye and haemorrhage.

hypothermia and complement system activation by a bypass bubble type oxygenator as possible causative factors. However, anaesthesia was uncomplicated and minimal blood loss occurred at operation in the cases we report. We propose that systemic hypotension and defective autoregulation of optic nerve blood flow with respect to intraocular pressure during bypass are a more likely cause of AION. Research in our departments has shown that the systemic arterial pressure drops immediately to about $70 \mathrm{mmHg}$ and the intraocular pressure rises briskly on commencement of cardiopulmonary bypass. ${ }^{9}$ Furthermore, increased circulating angiotensin could cause optic nerve ischaemia through its powerful vasoconstrictor effect on the ciliary vessels. Angiotensin rises substantially during bypass and particularly with nonpulsatile perfusion. ${ }^{10}$ It has been shown to cause defective autoregulation of optic nerve blood flow in response to change in intraocular pressure." The effect of this potent vasoconstrictor might be especially significant in a patient with known arterial disease.

Pressure on the globe might cause a rise in intraocular pressure, but a frame over the patient's face prevents pressure on the globe during the period of unconsciousness.

In conclusion, like other neurological complications of cardiopulmonary bypass, AION may occur in routine, seemingly uncomplicated operations, but, unlike most, it causes devastating long term disability. Clinical evidence of its occurrence may be unnoticed for days. Pathogenesis is uncertain, and no treatment is available. With increasing numbers undergoing coronary artery bypass surgery the need for awareness of AION has prompted this report.

\section{References}

1 Shaw PJ, Bates D, Cartlidge NEF, Heaviside D, Julian DG, Shaw DA. Early neurological complications of coronary artery bypass surgery. $\mathrm{Br}$ Med J 1985; 291 : 1384-7.

2 Hayreh SS. Anterior ischaemic optic neuropathy I. $\mathrm{Br} \mathrm{J}$ Ophthalmol 1974; 58: 955-63.

3 Hayreh SS. Blood supply of the optic nerve head and its role in optic atrophy, glaucoma, and oedema of the optic disc. Br J Ophthalmol 1969; 53: 721-48.

4 Eagling EM, Sanders MD, Miller SJH. Ischaemic papillopathy. BrJ Ophthalmol 1974; 58: 990-1008.

5 Sweeney PJ, Breuer AC, Selhorst JB, et al. Ischaemic optic neuropathy: a complication of cardio-pulmonary bypass surgery. Neurology 1982; 32: 560-2.

6 Drance SM, Morgan RW, Sweeney VP. Shock-induced optic neuropathy. N Engl J Med 1973; 288: 392-5.

7 Neuman RW, Maggiano JM, Frenkel M. Bilateral acute ischemic optic neuropathy in diabetes. Ann Ophthalmol 1978; 10: $1501-4$.

8 Cullen JF. Occult temporal arteritis. Br J Ophthalmol 1967; 51: 513-25.

9 Larkin DFP, Connolly P, Magner JB, Wood AE, Eustace P. Intraocular pressure during cardiopulmonary bypass. $\mathrm{Br} \mathrm{J}$ Ophthalmol in press.

10 Taylor KM, Morton JJ, Brannan JJ, Bain WH, Caves PK. The influence of pulsatile flow during cardiopulmonary bypass on the renin-angiotensin system and peripheral vascular resistance. $\mathrm{BrJ}$ Surg 1978; 65: 827.

11 Sossi N, Anderson DR. Blockage of axonal transport in optic nerve induced by elevation of intraocular pressure. Arch Ophthalmol 1983; 101: 94-7.

Accepted for publication 14 July 1986. 